\title{
La XXXII Muestra Nacional de Teatro
}

\section{Kirsten F. Nigro}

Del 4 al 12 de noviembre del 2011 se llevó a cabo en la ciudad de San Francisco de Campeche la XXXII Muestra Nacional de Teatro Mexicano. Patrocinada por el CONACULTA, el INBA, la Coordinación Nacional de Teatro y el Gobierno del Estado de Campeche (a través de la Secretaría de Cultura), la Muestra reunió a unas 32 compañías teatrales de todo el país, más críticos, dramaturgos, académicos, editores de revistas teatrales y de casas editoriales, así como a otros entusiastas del teatro mexicano (entre ellos la que escribe estas palabras). Durante más de una semana, la ciudad de Campeche se "vistió de teatro", abriendo las puertas de sus varios y excelentes recintos teatrales, como lo son el Teatro Juan de la Cabada, el Teatro del IMSS Ignacio García Téllez, el Teatro Universitario Joaquín Lanz, el elegante Teatro Francisco de Paula y Toro y el muy encantador Nuevo Circo Teatro Renacimiento (un número extraordinario de sedes para una ciudad provinciana de una población de 275,000 almas). Además, el centro histórico de Campeche y el Baluarte San Carlos de la muralla colonial que todavía circunda partes de la ciudad colonial se transformaron en espacios de representación escénica. La Muestra se inauguró con Discordia y una cuestión de amor de Lope de Rueda, en una producción Campeche-INBA, con dirección de Sandra Muñoz, y se cerró con Noches islámicas de Héctor Mendoza, producción de la Compañía Nacional de Teatro, con dirección de José Caballero. Entre estos paréntesis, hubo además puestas por compañías de Baja California, Guanajuato, Jalisco, Michoacán, Nuevo León, Puebla, Quintana Roo, San Luis Potosí, Sinaloa y Yucatán. En palabras de Teresa Vicencio Álvarez, Directora General del INBA, "la Muestra Nacional de Teatro [es] un foro que se ha convertido en la más importante reunión de obras y autores mexicanos en torno a esta disciplina, que con cada edición confirma su arraigo entre la comunidad y su potencial para demostrar a especialistas y público en general el abundante 


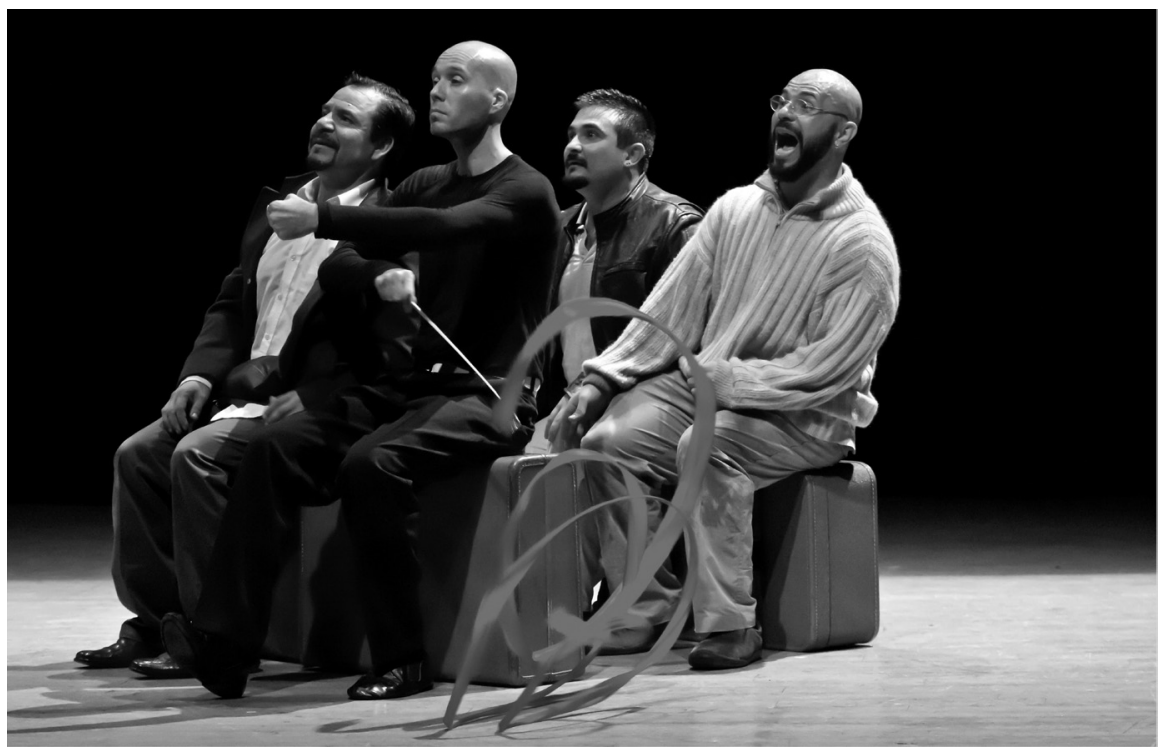

Cuerdas, Compañía Kreken. Foto: Enrique Gorostieta (egorostieta@gmail.com).

caudal que representa el teatro mexicano contemporáneo" (Programa de mano, "32 Muestra Nacional de Teatro", 2). Según todo lo que yo observé durante mis ocho días de asistencia, puedo confirmar lo dicho por Tere Vicencio y añadir que en cuanto al público campechano, su entusiasmo por la Muestra fue tal que había casa llena para todas (o casi todas) las funciones.

El propósito curatorial de la Muestra fue reunir puestas que trataran de "la realidad de nuestra ficción" o "la ficción de nuestra realidad" (Enrique Mijares, "Diario de la Muestra", Número 1, 5 de noviembre, 2); incluido en éste se planteó una temática global-la de hacer teatro en tiempos de violencia. Puede decirse que todas las obras en cartelera cumplieron con el propósito curatorial, ya que todo teatro de alguna manera cabe dentro de estos binomios (realidad/ficción, ficción/realidad), cualquiera que sea su referente extrateatral (mexicano o no); por ejemplo, las piezas para niños y jóvenes que exploran el mundo imaginativo y el afán lúdico de los niños (¿A qué jugamos? de Virginia Hernández, dirección de Sonia Ramírez Cotés, Compañía Del Tingo al Tango, Campeche), y Pipi, una obra para niños con complejo de meones, cuyo título resume todo de lo que trata (Jaime Chabaud, dirección Fausto Ramírez, A la Deriva Teatro, Jalisco); piezas que tratan de la amistad entrañable entre hombres (Espringbréiquer de Saúl Enríquez, Compañía Nuncamerlot/La Bambalina, Quintana Roo) y de los lazos inquebrantables de 
la amistad femenina en Roma al final de la vía (Daniel Serrano, dirección de Alberto Lomnitz, Viaje Redondo Producciones, Distrito Federal), así como de las disfunciones y enajenaciones familiares (Cuerdas de Bárbara Colio, dirección de Richard Viquiera, Compañía Kreken Teatro, Distrito Federal y El padre pródigo de Flavio González Mello, dirección de Martín Erazo Perales, Teatro de Babel, Distrito Federal). Todas estas piezas son ficciones teatrales que tratan de las realidades por las que cualquier ser humano pasa, $\mathrm{y}$ a la vez, dejan ver claramente que estas realidades son ficciones en el sentido de ilusiones, sueños, mentiras, desengaños. Otras obras seleccionadas para la Muestra planteaban temas ontológicos, como el de los espejismos entre el bien y el mal, entre el paraíso y el infierno que atormentan a los personajes de Luna hiena (Brígido Redondo Domínguez, dirección de Jorge Castro Realpozo, Campeche) o los misterios de Dios en El que mueve los hilos o cómo acabar por una vez por todas con las dudas sobre la existencia de Dios, las historias policíacas y las propagandas subliminales de cerveza (adaptación de un cuento de Woody Allen para teatro de títeres, Rafael Curci, Compañía Susy López-Títeres, Distrito Federal).

Dentro del panorama total de la Muestra, sin embargo, lo que predominó fueron obras que tratan del juego de realidades mexicanas-implícita o explícitamente - elaboradas en ficciones teatrales. Y así, inevitablemente, la violencia rondaba cada noche por los escenarios de Campeche. Hubo obras de corte realista (en su texto narrativo aunque no siempre en el escénico), como Consumatum Oxxo de Alejandro Román (director Jesús Coronado, Compañía El Cráneo de San Luis Potosí), con cuatro personajes en batalla armada, en un escenario casi del todo vacío; o Un año de silencio, en que tres personajes recuerdan su cruce de la frontera y la violencia que marca su vida de emigrados (escrito por Rafael Martínez, dirección de Alberto Ontiveros, Gorguz Teatro, Nuevo León) y Curva peligrosa del juarense Pilo Galindo (director Rodolfo Guerrero, Producciones Niebla de Recreo de Michoacán), en la cual se sigue la curva peligrosa que viven los adolescentes en un México acosado por la muerte y la pobreza. Tanto Memorama de Mario Cantú Toscano (dirección de Daniel Serrano, Compañía DramaRed de Baja California) como De insomnio y medianoche, cuentos para espantar gatas (Edgar Chías con dirección de Miguel Lugo, La Nada Teatro, Jalisco) exploran la relación ambigua y contradictoria entre victimario y víctima, desarrollada dentro de espacios cerrados, con una violencia latente que no termina de irrumpir del todo. 


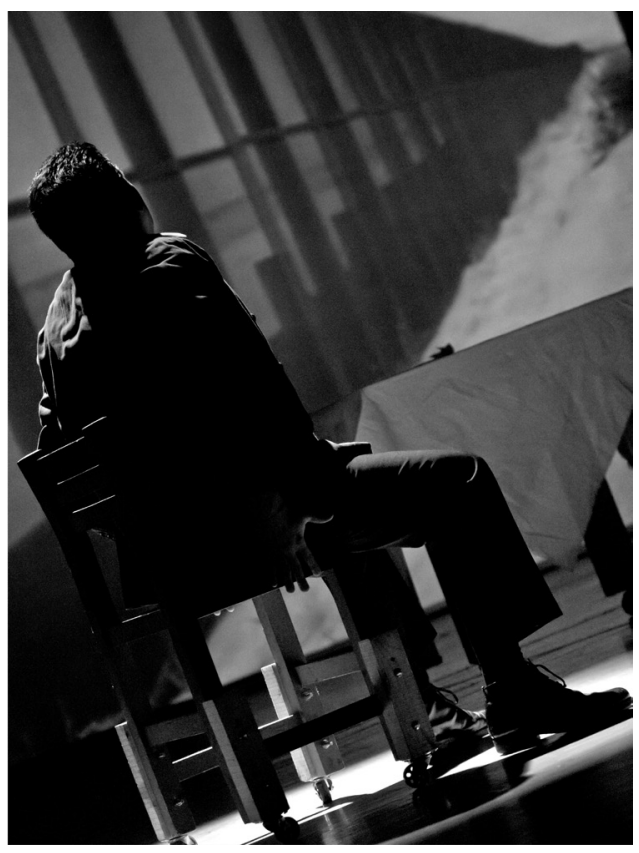

La razón blindada, 24th Street Theatre-Teatro Apolo y TLAUS de Sinaloa. Foto: Enrique Gorostieta (egorostieta@gmail.com).

Aunque la Muestra es la oportunidad de aplaudir la dramaturgia mexicana, también tiene como propósito dar a conocer las escenificaciones mexicanas de obras que vienen de otros países. Este año hubo el casi inevitable montaje de una obra shakesperiana (Ricardo III, dirección de Angel Norzagaray, Compañía Mexicali a Secas), pero las tres obras extranjeras que más llamaron la atención fueron El dragón dorado del alemán Roland Schimmelpfennig (director Daniel Giménez Cacho, Teatro UNAM y Por Piedad Teatro, Distrito Federal), La razón blindada de Arístides Vargas, co-producción de $24^{\text {th }}$ Street Theatre-Teatro Apolo (Los Ángeles) y TLAUS de Sinaloa, y

La inauguración del recientemente fallecido Václav Havel (dirección de David Psalmon, TeatroSinParedes, Distrito Federal). Aunque son obras bastante diferentes en su contenido y método teatral, todas tienen como blanco de su sátira la deshumanización: por la gesticulación política en La razón blindada, por la globalización que reduce todo a la producción de bienes de consumo (la comida rápida china y los migrantes ilegales que la cocinan en El dragón dorado) y la obsesiva necesidad de acumular objetos (el famoso "stuff" en inglés) para comprobar que existimos (La inauguración). Es interesante notar que esta violencia contra nuestra humanidad, al igual que la violencia más notablemente mexicana en las obras comentadas anteriormente, puede considerarse de alguna manera el fondo "dramático" a otro fenómeno violento que se subrayó en la Muestra: el suicidio en una generación de jóvenes que parece no ver otro escape a su situación existencial posmoderna (Immolación de Enrique Olmos de Ita, dirección Rodolfo Guerrero, Producciones Niebla de Recreo, Michoacán) y El viaje inmóvil, estudio en espiral sobre el suicidio (dirección de Jorge Vargas, Murmurante Teatro Producciones, Yucatán). 
No es posible en tan corto espacio hacer referencia específica al menú completo de obras que se ofreció en la Muestra y he tenido que dejar por fuera obras interesantes de dramaturgos y grupos tan importantes como lo son Juliana Faesler y su compañía La Máquina de Teatro, La Rendija de Raquel Araujo y Alberto Villarreal y su compañía 06-10. Tampoco me ha sido posible entrar en gran detalle sobre la rica programación de mesas, talleres, conferencias y presentaciones de libros que se ofreció durante la Muestra. Pero es importante señalar que fue en ésta donde se recalcaron los temas más palpitantes para el mundo teatral mexicano: la política de la descentralización de las artes teatrales, la necesidad de un mejor entrenamiento de los artistas teatrales (especialmente en cuanto al uso de la voz del actor, aspecto que era notablemente pobre en muchas de las puestas) y, desde luego, cómo hacer teatro en tiempos de violencia. A esta última pregunta no hubo una respuesta única, un desacuerdo que en momentos produjo una palpable tensión entre los interlocutores. Lo que se debatía con ánimo y pasión era más que nada qué tipo de teatro debe hacerse cuando el país está empapado de violencia: ¿un teatro que refleja o reproduce esta violencia? ¿O uno que no tanto la evade sino que le ofrece al público un breve descanso de ella? Las palabras más elocuentes al respecto fueron de Medardo Treviño de Tamaulipas, quien habló de cómo hacer teatro literalmente dentro de la violencia, con balaceras en frente de los teatros y amenazas de muerte a la comunidad teatrista.

En su mayoría, los participantes en la XXXII Muestra Nacional de Teatro quedaron bastante contentos con el evento, algo que se dejó ver en las encuestas que se hicieron a diario. Como es el caso en todo encuentro de este tipo, algunas cosas no gustaron, por ejemplo (y además de algunas de las puestas): la programación de cinco obras en una sola noche, el hospedaje de las compañías teatrales en diferentes hoteles, la presencia de tantas obras del D.F. (una queja que hizo eco de lo que algunos llamaron la "violencia" de la centralización de las artes en México). Pero dos cosas gustaron a todos: la bellísima cuidad de Campeche y los muy hospitalarios campechanos, que se ganaron el premio gordo en todas las encuestas. Para los que tienen curiosidad, comparto lo que más me gustó a mí como anónima y muy callada observadora (quien por desgracia no pudo probar todas las ofertas de la Muestra): 1) textos dramáticos: Malinche/Malinches de Juliana Faesler (por no olvidarse de los temas de la mujer); Roma al final de la via (por ahondar tan profundamente en la amistad entre mujeres); Desierto bajo escenografia lunar de Alberto Villarreal (por su excentrismo e imaginación lunática; 2) escenografía: El dragón dorado (por la creatividad del espacio claustrofóbico 


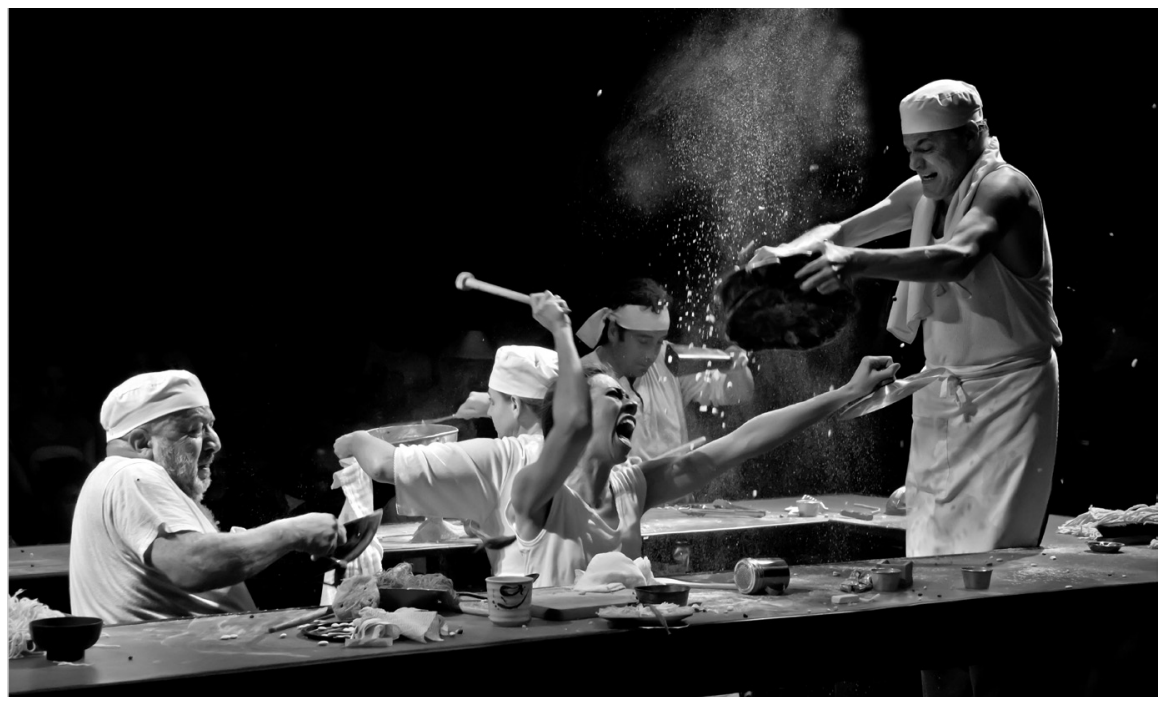

El dragón dorado, Teatro UNAM y Por Piedad Teatro.

Foto: Enrique Gorostieta (egorostieta@gmail.com).

de la cocina del restaurante chino; La inauguración (por el uso espléndido de la multimedia); Cuerdas (por crear lo máximo con lo mínimo); 3) director: Daniel Serrano (por el control y la precisión del montaje de Memorama); Daniel Giménez Cacho (por no perder nunca la cordura en su dirección de la locura frenética de El dragón dorado); 4) actores: Jesús Castaños Chima y Arturo Díaz de Sandy en La razón blindada (por su energía, comicidad y el contrapunteo perfecto de sus diálogos); 5) actrices: Julieta Ortiz y Norma Angélica en Roma al final de la vía (por captar de manera tan vital y tan tierna la amistad entre sus personajes); 6) trabajo actoral de ensemble: todo el elenco de El dragón dorado (por su increíble talento y por hacerme reír y recordar las locuras de los hermanos Marx); 7) un aplauso especial mío para Enrique Olmos de Ita y su obra Immolación (por hacerme a mí y a todos los demás adultos de cierta edad en el público confrontar la crisis del suicidio entre los jóvenes, y por aprovechar de un teatro cuyo uso de la cibertécnica es espejo de las realidades de esta misma juventud). Finalmente, lo que más me decepcionó: Nochas islámicas de la Compañía Nacional de Teatro, que, en resumidas palabras, fue "mucho ruido y pocas nueces", además de ser una muy curiosa y malhadada selección dentro de todos los posibles textos de Héctor Mendoza para rendirle homenaje al gran maestro. 